\title{
Implications of Model Selection: A Comparison of Publicly Available, CONUS-Extent Hydrologic Component Estimates - Supplement
}

Samuel Saxe ${ }^{1,2}$, William Farmer ${ }^{1}$, Jessica Driscoll ${ }^{1}$, Terri S. Hogue ${ }^{2,3}$

${ }^{1}$ Analysis and Prediction Branch, U.S. Geological Survey, Lakewood, CO 80225, U.S.

$5 \quad{ }^{2}$ Hydrologic Science and Engineering, Colorado School of Mines, Golden, CO 80401, U.S.

${ }^{3}$ Department of Civil and Environmental Engineering, Colorado School of Mines, Golden, CO 80401, U.S.

Correspondence to: Samuel Saxe (ssaxe@usgs.gov)

\section{Appendix 1}

Acronym

\section{Hydrologic Models}

CPC

CSIRO-PML

ERA5/H-TESSEL
Climate Prediction Center

Rootzone soil moisture (equivalent water depth) estimated through a one-layer water balance model forced by CPC reanalysis precipitation and temperature. Resolutions are monthly at $1 / 2^{\circ}$ from 1948 to present for the globe (Fan and van den Dool, 2004). Author's acknowledgement: CPC soil moisture data provided by the NOAA/OAR/ESRL PSD, Boulder, Colorado, USA, from their Web site at https://www.esrl.noaa.gov/psd/.

Commonwealth Scientific and Industrial Research Organisation

Estimates of evapotranspiration generated by a spatially explicit Penman-Monteith-Leuning model constrained annually by the Fu hydroclimatic model. The model is driven by precipitation, temperature, vapour pressure, windspeed, and radiation estimates. Datasets used include reanalysis climatology and meteorology products and ex-situ surface and vegetation data. Resolutions are monthly at $1 / 2^{\circ}$ spatial resolution from 1981-2012 for the globe (Zhang et al., 2016).

Hydrology revised-Tiled ECMWF Scheme for Surface Exchanges over Land forced with the ERA5 reanalysis

From the European Centre for Medium-Range Weather Forecasts (ECMWF), a land surface model, improved from the original TESSEL model, estimates land surface and subsurface fluxes and stores. The modeled is structured with four soil layers (0-7, 7-28, 28-100, 100-289 cm), a 
single snow layer, two sub-grid vegetation types, and spatially variant soil type. This paper uses model output forced with ERA5 reanalysis data (see below), provided by C3S in conjunction with the reanalysis product. Resolutions are hourly at $0.25^{\circ}$ from 1979 to present for the globe (Balsamo et al., 2009; C3S, 2017). Author's acknowledgement: Contains modified Copernicus Climate Change Service Information [2019].

ERA5-Land/H-TESSEL

Hydrology revised-Tiled ECMWF Scheme for Surface Exchanges over Land forced with the ERA5-Land reanalysis

From the ECMWF, a land surface model, improved from the original TESSEL model, estimates land surface and subsurface fluxes and stores. See above for a description of model structure. This paper uses model output forced with ERA5-Land reanalysis data (see below), provided by C3S in conjunction with the reanalysis product. Resolutions are hourly at $0.1^{\circ}$ from 2001 to present for the globe (Balsamo et al., 2009; C3S, 2019). Author's acknowledgement: Contains modified Copernicus Climate Change Service Information [2019].

\section{GLDAS-CLM}

Community Land Model, V2 driven by the NASA GLDAS

From the National Aeronautics and Space Administration (NASA) Global Land Data Assimilation System (GLDAS), a single-column land surface model that estimates surface and subsurface fluxes and stores within independent spatial domains. The model is structured with variable layer spacing for soil temperature and moisture, multilayer snow process parameterization, TOPMODEL-concept runoff parameterization, a canopy photosynthesisconductance model, and tiling treatments for sub-grid energy and water balances. Model input requirements are land surface types, soil and vegetation parameters, model initialization states, and climatological forcing data. This study uses the operational version driven by the NASA GLDAS. Resolutions are sub-daily at $1^{\circ}$ from 1979 to present for the globe (Dai et al., 2003; Rodell et al., 2007a, 2004).

\section{GLEAM}

Global Land Evaporation Amsterdam Model

Estimates land evaporation, surface soil moisture, rootzone soil moisture, potential evaporation, and evaporative stress conditions. Potential evapotranspiration is calculated using the Priestly-Taylor equation on reanalysis, in-situ, and ex-situ meteorological measurements. Actual evapotranspiration is calculated using an evaporative stress factor based on rootzone soil moisture estimates and microwave ex-situ observations. Rootzone soil 
moisture is estimated through a water balance model. Model generation 3.3 replaces reanalysis measurements from ERA-Interim with ERA-5 (see below). Model version $3.3 b$ differs from $3.3 a$ by utilizing primarily ex-situ data, excluding reanalysis products. Resolutions are daily at $1 / 4^{\circ}$ from 1980 to present for the globe (Martens et al., 2017; Miralles et al., 2011).

JRA-25/SiB

JRA-55/SiB

Livneh-VIC

MERRA-Land/CLSM
Simple Biosphere model forced with Japanese 25-year Reanalysis

Land surface flux and store estimates generated as output from the Japan Meteorological Agency (JMA)-operated Simple Biosphere model (SiB) forced with Japanese 25-year ReAnalysis (JRA-25) reanalysis. The predecessor to modern land surface models such as Mosaic, the model is biophysically based and structured with two vegetation layers (canopy and ground cover), and three soil layers. Resolutions are sub-daily to daily at T106 ( 110 km) from 1979 to 2004 for the globe (NCAR Research Staff (Eds), 2016; Onogi et al., 2007; Sellers et al., 1986).

Simple Biosphere model forced with Japanese 55-year Reanalysis

Land surface flux and store estimates generated as output from the JMA-operated SiB model forced with Japanese 55-year ReAnalysis (JRA-55) reanalysis. See above for model description. Resolutions are sub-daily to daily at T319 ( 55 km) from 1957 to present for the globe (Kobayashi et al., 2015; Kobayashi and NCAR Research Staff (Eds), 2019; Sellers et al., 1986).

Variable Infiltration Capacity (VIC) model forced and calibrated by Livneh et al. 2013

Modeled estimates of soil moisture, snow water equivalent, discharge, and surface heat fluxes generated by forcing the VIC model with the Livneh et al. 2013 reanalysis meteorological dataset (see below). See below (NLDAS2-VIC) for description of model structure. Resolutions are sub-daily to daily at $1 / 16^{\circ}$ from 1915 to 2011 for the conterminous United States (Liang et al., 1994; Livneh et al., 2013).

Catchment Land Surface Model forced with MERRA-Land reanalysis

A land surface model developed to improve treatment of horizontal hydrologic process in response to previous land surface model over-attention to vertical processes. The model is structured around tiled hydrologic catchments defined by topography, two soil layers, and three snow layers. This paper uses surface estimates generated from the MERRA-Land-forced 
version from GEOS-5, released in conjunction with the MERRA-Land reanalysis product (see below). Resolutions are sub-daily at 1/2 ${ }^{\circ}$ from 1980 to 2016 for the globe (Koster et al., 2000; Reichle et al., 2011; Rienecker et al., 2011).

MERRA-2/CLSM

NCEP-DOE/Eta-Noah

NCEP-NARR/Eta-Noah
Catchment Land Surface Model forced with MERRA-2 reanalysis

A land surface model estimating surface and subsurface hydrologic fluxes and stores. See above for model description. This paper uses estimates generated from the MERRA-2-forced version from GEOS-5, released in conjunction with the MERRA-2 reanalysis product (see below). Resolutions are sub-daily at $1 / 2^{\circ}$ from 1980 to present (Gelaro et al., 2017; Reichle et al., 2017).

Noah land surface model forced with National Centers for Environmental PredictionDepartment of Energy, R-2 reanalysis

Noah land surface model estimates surface and subsurface hydrologic fluxes. See below (NLDAS2-Noah) for model description. Model estimates here are generated through the Noah land surface model component of the NCEP Eta atmospheric model forced with NCEP-DOE reanalysis (see below), released in conjunction with the NCEP-DOE product. Resolutions are sub-daily at T62 ( 210 km) gridding from 1979 to present for the globe (Kalnay et al., 1996; Kanamitsu et al., 2002). Author acknowledgment: NCEP_Reanalysis 2 data provided by the NOAA/OAR/ESRL PSD, Boulder, Colorado, USA, from their Web site at https://www.esrl.noaa.gov/psd/.

Noah land surface model forced with National Centers for Environmental Prediction-North American Regional Reanalysis

Noah land surface model estimates produced as a component of the larger Eta atmospheric model. See below (NLDAS2-Noah) for model description. Model estimates here are generated through the Noah surface model component of the NCEP Eta atmospheric model forced with NCEP North American Regional Reanalysis (NCEP-NARR), released in conjunction with the NCEP-NARR product. Resolutions are sub-daily at $32 \mathrm{~km}$ from 1979 to present for North America (Mesinger et al., 2006). Author acknowledgement: NCEP Reanalysis data provided by the NOAA/OAR/ESRL PSD, Boulder, Colorado, USA, from their Web site at https://www.esrl.noaa.gov/psd/. 
A water balance model applied within the U.S. Geological Survey's National Hydrologic Model framework that utilizes a monthly accounting procedure to estimate evapotranspiration, runoff, soil moisture, and snow water equivalent based on methodology from Thornthwaite (1948). Resolutions are monthly at Hydrologic Response Units from 1949 to 2010 for the conterminous United States (McCabe and Markstrom, 2007).

\section{NHM-PRMS}

NLDAS2-Mosaic

NLDAS2-Noah
National Hydrologic Model-framework Precipitation Runoff Modeling System

A process-based, deterministic hydrologic model applied within the framework of the U.S. Geological Survey's National Hydrologic Model that estimates various surface and subsurface fluxes and stores using a conceptualized watershed composed of a series of reservoirs, stream segments, and lakes maintained with a balanced water budget. The model utilizes reanalysis and ex-situ physical characteristic data of topography, soils, vegetation, geology, and land use to derive required parameters, and is driven by precipitation and temperature reanalysis products. Resolutions are daily at Hydrologic Response Units from 1980 to 2016 for the conterminous United States (Markstrom et al., 2015; Regan et al., 2018).

Mosaic model driven by the NASA NLDAS, Phase 2

A land surface model, directly descended from the SiB land surface model, that estimates surface and subsurface fluxes and stores, originally targeted to be coupled with climate and weather models. The model is structured to allow vegetation control over surface energy and water balances, a canopy interception reservoir, three soil reservoirs (thin surface, middle "rootzone", and lower "recharge"), and a complete snow budget. The model name is derived from the mosaic approach of tiling sub-grid cells into homogeneous vegetation types with independent energy balances. This study uses the operational version driven by the NASA NLDAS Phase 2 (see below), wherein the model was configured to support up to 10 tiles per grid cell, each with specified predominant soil types and three spatially invariant soil layers. Resolutions are hourly at 1/8 from 1979 to present for North America (Koster and Suarez, 1996; Youlong Xia et al., 2012b; Y. Xia et al., 2012b).

Noah model driven by the NASA NLDAS, Phase 2

A grid-based land surface model, simpler than the Noah-MP version, originally developed as a component of the NOAA-NCEP Eta model and updated for use in the NASA NLDAS, Phase 
2 (see below), and is used within the Weather Research and Forecasting (WRF) atmospheric model, the National Oceanic and Atmospheric Administration-NCEP Climate Forecast System (NOAA-NCEP CFS), and the NOAA Global Forecast System. The model is structured with four spatially invariant thickness soil layers (three layers forming the rootzone system in nonforested regions and four in forested regions) and can simulate soil freeze-thaw processes. This study uses the operational version (Noah-2.8) driven by the NASA NLDAS, Phase 2 (see below). Resolutions are hourly at $1 / 8^{\circ}$ from 1979 to present for North America (Ek et al., 2003; Youlong Xia et al., 2012b; Y. Xia et al., 2012a).

NLDAS2-VIC

SNODAS

TerraClimate

\section{Variable Infiltration Capacity model driven by the NLDAS, Phase 2}

A semi-distributed, grid-based hydrologic model estimating surface and subsurface fluxes and stores. Model structure is composed of three soil layers (top spatially invariant $10 \mathrm{~cm}$ thickness, others spatially-variant) with rootzone depth controlled by vegetation. The model utilizes subgrid vegetation tiling similar to the Mosaic land surface model (see above), and a two-layer energy balance snow model. This study uses the operational version driven by the NASA NLDAS, Phase 2 (see below). Resolutions are hourly at 1/8 from 1979 to present for North America (Liang et al., 1994; Youlong Xia et al., 2012b; Y. Xia et al., 2012c).

\section{SNOw Data Assimilation System}

Estimates snow cover and snow water equivalent by integrating modeled snow estimates with observational and reanalysis data from in-situ and ex-situ sources. The primary estimation method is a physically based, spatially-distributed energy-and mass-balance snow model forced by downscaled output from the National Weather Service Rapid Refresh weather forecast model. In-situ and ex-situ data sources are applied depending on difference fields between modeled and observed values, and used to perform immediate model calibrations. Resolutions are daily at $1 \mathrm{~km}$ from 2003 to present for North America (Barrett, 2003; National Operational Hydrologic Remote Sensing Center, 2004).

\section{TerraClimate}

A dataset utilizing both reanalysis and water budget modeling to generate estimates of climate, meteorological, and hydrologic variables. Climate and meteorological estimates are calculated by applying interpolated time-varying anomalies from both CRU Ts4.0 and JRA-55 to the higher resolution WorldClim climatology. Hydrologic estimates of evapotranspiration, 
precipitation, temperature, and soil water capacity are generated through a modified Thornthwaite-Mather climatic water balance model. Water balance-derived resolutions are monthly at $1 / 2^{\circ}$ from 1958 to present for the globe (Abatzoglou et al., 2018).

VegET

Vegetation ET

Estimates rootzone soil moisture and evapotranspiration through a precipitation-driven onedimensional rootzone water balance model. Because the model is parameterized to operate on a control volume using water holding capacity, it captures only evapotranspiration from vegetation sources (i.e. natural conditions) and does not consider anthropogenic (i.e. nonnatural) water use. Data provided via personal correspondence with the authors. Resolutions are daily at $1 \mathrm{~km}$ from 2000 to 2014 for the conterminous United States (Senay, 2008; Velpuri and Senay, 2017).

\section{Reanalysis}

CanSISE

Canadian Sea Ice and Snow Evolution Network, V2

Estimates snow water equivalent (SWE) by merging five observation-based estimates through an adapted ensemble mean methodology. Merged products are (1) GlobSnow-combined SWE (merges ex-situ passive microwave and in-situ weather station observations), (2) ERA-Interim reanalysis, (3) MERRA reanalysis, (4) SWE from the Interaction Sol-Biosphère-Atmosphère (ISBA) land surface model forced with ERA-Interim reanalysis (see below), and (5) NASA Global Land Data Assimilation System reanalysis. Resolutions are daily at $1^{\circ}$ from 1981 to 2010 for the Northern Hemisphere (Mudryk et al., 2015; Mudryk and Derksen, 2017).

CMAP

CPC Merged Analysis of Precipitation

From the CPC, estimates precipitation by blending various in-situ, ex-situ, and reanalysis datasets. The "Standard" product estimates precipitation by blending ex-situ Global Precipitation Index (GPI), OLR Precipitation Index (OPI), Special Sensor Microwave/Imager (SSM/I) emission, and Microwave Sounding Unit (MSU) data with in-situ precipitation gauge measurement data. The "Enhanced" product additionally includes blended NCEP-NCAR reanalysis (see below) precipitation estimates. Resolutions are monthly at $21 / 2^{\circ}$ from 1979 to present for the globe (Xie and Arkin, 1997). Author's acknowledgement: CMAP Precipitation 
data provided by the NOAA/OAR/ESRL PSD, Boulder, Colorado, USA, from their Web site at https://www.esrl.noaa.gov/psd/.

DayMET

ERA5

ERA5-Land

GPCC
Daily Surface Weather Data on a 1-km Grid for North America, V3

Version 3 of the DayMET model, generates estimates of temperature, precipitation, radiation, vapor pressure, snow water equivalent, and day length from in-situ observations of temperature and precipitation and digital elevation data. Interpolation is performed using the spatial convolution of a truncated Gaussian weighting filter with an iterative station density algorithm applied to heterogeneous observation distribution in complex terrain. Snow water equivalent is estimated using a simple temperature-based snowmelt model from Running and Coughlan (1988). This paper assigns DayMET snow water equivalent estimates to the "Reanalysis" category because of the snow model's simplicity and lack of a physical or conceptual hydrologic framework. Descriptions of the current model framework are best described at the ORNL DAAC website (daac.ornl.gov/DAYMET/guides/Daymet_V3_CFMosaics.html). Resolutions are daily at $1 \mathrm{~km}$ from 1980 to present for North America (Thornton et al., 2017, 2000, 1997).

ECMWF ReAnalysis, Fifth Product

Generates numerous estimates of climate and meteorological variables by assimilating observational data from 55 ex-situ and 19 in-situ sources using the 4D-Var variational method. Previous generations of the ERA product were FGGE, ERA-15, ERA-40, and ERA-Interim, all now out of service. Resolutions are hourly at $0.25^{\circ}$ from 1979 to present for the globe (C3S, 2017). Author's acknowledgement: Contains modified Copernicus Climate Change Service Information [2019].

ECMWF Reanalysis, Fifth Product

Estimates of climate, meteorological, and surface hydrology fluxes by replaying the ERA5 reanalysis (see above) land component at higher spatial resolution. Resolutions are hourly at $0.1^{\circ}$ from 2001 to present for the globe (Balsamo et al., 2009; C3S, 2019). Author's acknowledgement: Contains modified Copernicus Climate Change Service Information [2019].

Global Precipitation Climatology Centre 
Monthly accumulated precipitation estimates based on 67,200 in-situ observational stations with decade or longer temporal spans. The dataset used in this paper is V7, one of two GPCC Full Data Products, which the product's authors suggest are the highest accuracy of their datasets. Resolutions are monthly at $1 / 2^{\circ}$ from 1901 to 2013 for the globe (Becker et al., 2013; Schneider et al., 2011). Author's acknowledgement: GPCC Precipitation data provided by the NOAA/OAR/ESRL PSD, Boulder, Colorado, USA, from their Web site at https://www.esrl.noaa.gov/psd/

gridMET

Livneh et al. 2013

Maurer et al 2002
gridMET (or, METDATA)

Estimates temperature, precipitation, downward shortwave radiation, wind-velocity, humidity, relative humidity, and specific humidity by blending PRISM reanalysis (see below) climate data with NLDAS2 reanalysis (see below) data. Resolutions are daily at 1/24 from 1979 to present for the conterminous United States (Abatzoglou, 2013).

Livneh daily CONUS near-surface gridded observed meteorological data Near-surface meteorological estimates generated from approximately 20,000 NOAA Cooperative Observer station daily datasets. Precipitation and temperature in-situ observations are converted to grids using the synergraphic mapping system, wind data linearly interpolated from the lower resolution NCEP-NCAR reanalysis dataset. Other variables were derived using methods from the mountain microclimate simulator. Daily temperature data is converted to 3-hourly using spline interpolation. Resolutions are daily at $1 / 16^{\circ}$ from 1915 to 2011 for the conterminous United States (Livneh et al., 2013). Author acknowledgement: Livneh data provided by the NOAA/OAR/ESRL PSD, Boulder, Colorado, USA, from their Web site at https://www.esrl.noaa.gov/psd/.

Maurer et al. 2002

Meteorological and surface hydrologic estimates generated through both reanalysis and hydrologic modeling. Precipitation gridded from in-situ daily measurement stations using the synergraphic mapping system algorithm scaled to match PRISM (see below) long-term averages. Surface estimates derived through the VIC (see above) hydrologic model. Resolutions are daily at 1/8 from 1950-1999 for North America (Maurer et al., 2002). 

variables

The predecessor to MERRA-2 (see below) estimates meteorological and surface hydrologic components. Meteorological estimates are derived through the GEOS-5 atmospheric general circulation model by assimilating in-situ (3DVAR analysis algorithm) and ex-situ (Community Radiative Transfer Model) observational data. This paper uses the Land Surface Diagnostics precipitation. Resolutions are sub-daily at $1 / 2^{\circ}$ from 1980 to 2016 for the globe (Rienecker et al., 2011).

MERRA-2

NCEP-DOE

NLDAS2
Modern-Era Retrospective analysis for Research and Applications, V2

The most recent version of the MERRA product differs from MERRA-land by including updates to models, algorithms, observing systems, and ex-situ processing methods, as well as 14 additional ex-situ data sources. Precipitation is derived from global precipitation products disaggregated to hourly time steps using MERRA-Land precipitation. Precipitation estimates used in this paper are from the Land Surface Diagnostics category. Resolutions are sub-daily at $1 / 2^{\circ}$ from 1980 to present (Gelaro et al., 2017).

National Centers for Environmental Prediction-Department of Energy, R-2

The updated $(R-2)$ version of the NCEP-NCAR reanalysis, estimates climate, meteorological, and surface hydrologic components. Reanalysis estimates of atmospheric variables are performed through assimilation and modeling of in-situ and ex-situ observational data. Resolutions are sub-daily at T62 ( 210 km) gridding from 1979 to present for the globe (Kalnay et al., 1996; Kanamitsu et al., 2002). Author acknowledgment: NCEP-DOE data provided by the NOAA/OAR/ESRL PSD, Boulder, Colorado, USA, from their Web site at https://www.esrl.noaa.gov/psd/.

North American Land Data Assimilation System, Phase 2

Compiled data used to drive land surface models (see above), including (1) land surface parameters of vegetation, soil, topography, and temperature; (2) surface forcing fields of precipitation, radiation, temperature, humidity, wind, and pressure derived by blending various in-situ and ex-situ datasets. Precipitation, specifically, is derived by blending temporally disaggregated reanalysis (CPC and NARR, see above) and ex-situ (Doppler Stage II and 
CMORPH) estimates. Resolutions are hourly at 1/8 from 1979 to present for North America (Youlong Xia et al., 2012b; Xia, NCEP/EMC, et al., 2009).

PRISM

Reitz et al 2017

UoD-v5

WaterWatch
Parameter-elevation Regressions on Independent Slopes Model

Reanalysis estimates of precipitation and temperature calculated using a climate-elevation regression model, utilizing information of location, elevation, coastal proximity, and other geophysical parameters. Resolutions are daily at $800 \mathrm{~m}$ (paid) and $4 \mathrm{~km}$ (free) from 1895 to present for the United States (PRISM Climate Group, OSU, 2004).

Reitz et al. 2017

Reanalysis estimates of groundwater recharge, quick-flow runoff, and evapotranspiration. Runoff and evapotranspiration are calculated using regression equations derived from observational water balance data using land cover, temperature, and precipitation information. Groundwater recharge is calculated as the remainder of a water balance using runoff, evapotranspiration, and precipitation. Resolutions are annual (monthly provided via personal correspondence with authors) at $800 \mathrm{~m}$ from 2000 to 2013 for the conterminous United States (Reitz et al., 2017).

University of Delaware Air Temperature and Precipitation, V5

Reanalysis precipitation and temperature estimates calculated from in-situ observational data with an interpolation algorithm based on the spherical Shepard's distance-weighting method with Digital Elevation Model information. This paper uses the fifth product version. Resolutions are monthly at 1/2 from 1950 to 1999 (Willmott and Matsuura, 2001). Author acknowledgement: UoD precipitation data provided by the NOAA/OAR/ESRL PSD, Boulder, Colorado, USA, from their Web site at https://www.esrl.noaa.gov/psd/.

WaterWatch

Estimates of runoff derived from the U.S. Geological Survey's in-situ streamgauge network. Resolutions are monthly at watershed, Hydrologic Unit Levels 2-8, and state polygons from 1901 to present (Jian et al., 2008).

\section{Remote Sensing}


Scientifically identical to Version 1 (updates to product maturity code in V2), estimates SWE using passive microwave data collected from the Advanced Microwave Scanning Radiometer - Earth Observing System (AMSR-E) instrument hosted on NASA's Aqua satellite. Microwave measurements are converted to SWE estimates using the AMSR-E Snow Water Equivalent Algorithm that utilizes brightness temperature differences calculated using the dense media radiative transfer equation and pre-selected snowpack profiles to develop an artificial neural network. Probable SWE estimate ranges are then restricted using surface temperature and land cover attributes derived from the ex-situ MODIS sensor hosted on the NASA Terra satellite. Resolutions are daily at $25 \mathrm{~km}$ from 2002 to 2011 for the globe (Chang et al., 2003; Chang and Rango, 2000; Tedesco et al., 2004).

ESA-CCI

European Space Agency - Climate Change Initiative

Volumetric soil moisture estimates generated by merging both active and passive ex-situ microwave data-derived soil moisture products into three products: ACTIVE, PASSIVE, and COMBINED. Passive microwave products are from the Scanning Multichannel Microwave Radiometer (SMMR), SSM/I, Tropical Microwave Imager (TMI), Advanced Microwave Scanning Radiometer - Earth Observing System (AMSR-E), WindSat, Soil Moisture and Ocean Salinity (SMOS), and AMSR2 sensors. Active microwave products are from the Active Microwave Instrument Wind Scatterometer (AMI-WS), Advanced SCATterometer - satellite A or satellites $A / B$ (ASCAT-A and ASCAT-A/B) sensors. Merging is performed by resampling target products to a uniform spatiotemporal structure, scaling to match ranges, and weighted using triple collocation. This research utilizes the COMBINED product. Resolutions are daily at 1/4 from 1978 to present for the globe (Dorigo et al., 2017).

GPCP-v3

Global Precipitation Climatology Project, V3 Precipitation Data (Beta)

Estimates of precipitation generated by assimilating radiometer data from SSMI and SSMIS, infrared data from the Precipitation Estimation from Remotely Sensed Information using Artificial Neural Networks - Climate Data Record (PERSIANN-CDR), TIROS Operational Vertical Sounder (TIROS-TOVS) sensor and Tropical Rainfall Measuring Missing (TRMM) Combined Climatology precipitation estimates with the GPCC global gauge analysis (see above in "Reanalysis"). This paper uses the "combined satellite-gauge" product rather than 
the "satellite-only" product. Resolutions are monthly at 1/2 ${ }^{\circ}$ from 1983 to 2016 for the globe (Huffman et al., 2019).

MOD16-A2

SMOS-L4

SSEBop

TMPA-3B43
MODIS Global Evapotranspiration Project

Level 4 Moderate Resolution Imaging Spectroradiometer (MODIS) land data product that estimates evapotranspiration from ex-situ observational MODIS vegetation data and reanalysis meteorological data using an improved evapotranspiration model (Mu et al., 2011) based on the Penman-Monteith equation. Resolutions are 8-day at $1 \mathrm{~km}$ from 2000-2010 for the globe (Running et al., 2017).

Soil Moisture and Ocean Salinity - Level 4

Volumetric rootzone soil moisture estimates derived using CATDS-generated ascending and descending orbit SMOS L3 surface volumetric soil moisture estimates in conjunction with MODIS sensor-derived vegetation information, reanalysis NCEP climate data, FAO soil textures, and ECOCLIMAP surface cover. A double bucket model, composed of a simple water budget model (5-40 cm depth) and a budget model based on a linearized Richard's Equation formulation (40-200 cm depth), is used to extrapolate surface SMOS L3 soil moisture $(0-5 \mathrm{~cm})$ to the rootzone domain. This study merged the ascending and descending orbit products by mean. Resolutions are daily at $25 \mathrm{~km}$ EASE Grids from 2010 to 2017 for the globe (Al Bitar et al., 2013).

Operational Simplified Surface Energy Balance model

A parameterization of the Simplified Surface Energy Balance approach that estimates evapotranspiration from ex-situ MODIS vegetation, ex-situ Shuttle Radar Topography Mission (SRTM) elevation data, reanalysis meteorological data, and other modeled data using an energy balance approach where actual evapotranspiration is calculated as the difference between net surface radiation, sensible heat flux, and ground heat flux. Resolutions are monthly at $1 \mathrm{~km}$ from 2000 to 2014 for the conterminous United States and portions of surrounding countries (Senay et al., 2013, 2011).

TRMM Multisatellite Precipitation Analysis, V7

From the larger Tropical Rainfall Measuring Mission (TRMM), generates spatiotemporally continuous precipitation estimates by merging precipitation estimates from numerous ex-situ 
data sources. Primary data sources include (1) passive microwave data from various low earth orbit satellites (e.g. TRMM, AMSR-E) that are converted to precipitation estimates using source-specific algorithms; (2) infrared data collected by geosynchronous earth orbit satellites; (3) TRMM Combined Instrument estimate, a merged passive microwave and active radar product; 4) in-situ GPCP and CAMS monthly precipitation measurements. Resolutions are sub-daily at $1 / 4^{\circ}$ from 1998 to present for the globe (Huffman et al., 2010, 2007).

10 


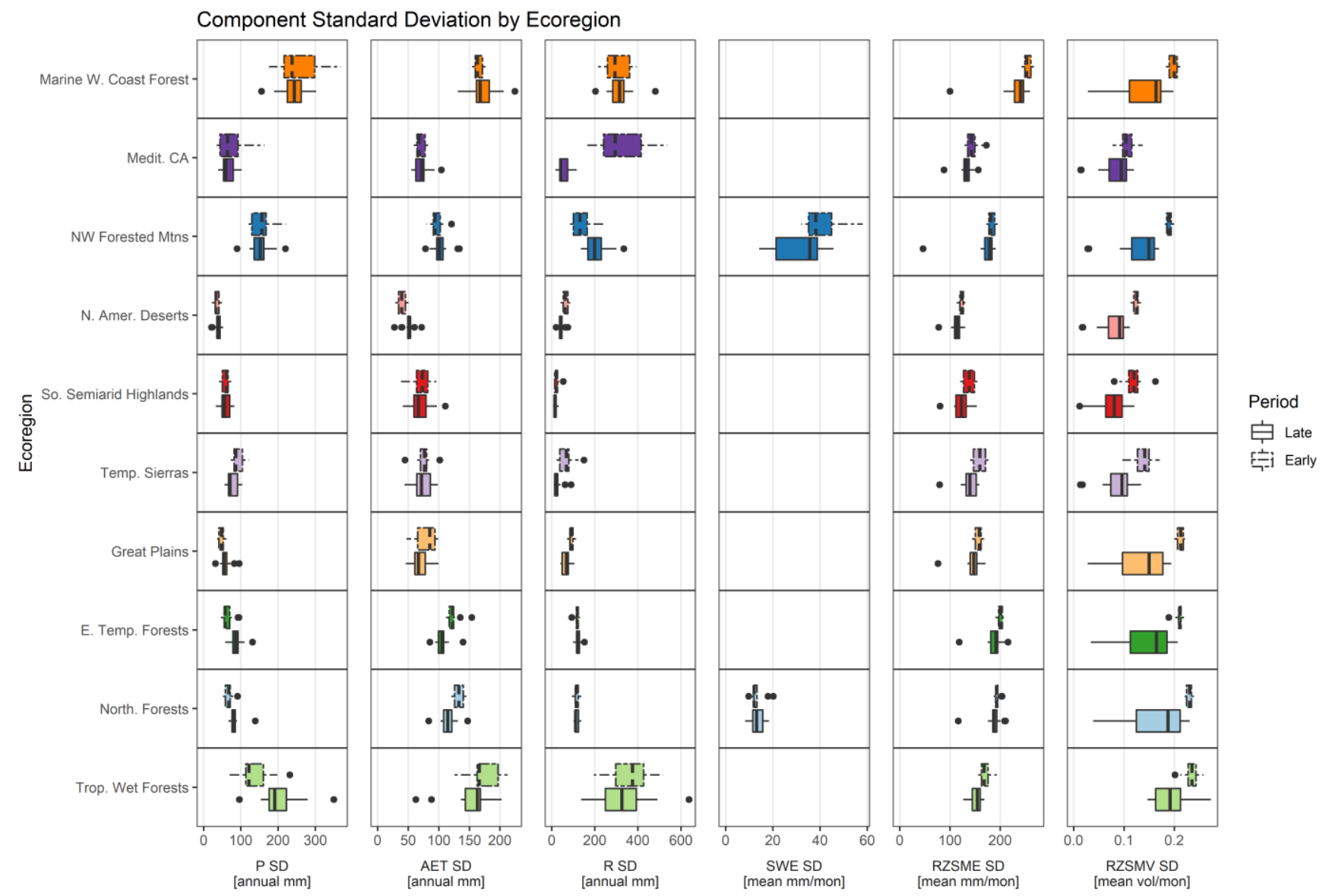

Figure A2.1: Boxplots of annual standard deviation (SD) between component estimates at ten ecoregions. SD distributions are subdivided into two periods, 1985-1999 and 2000-2014. Box lower limits, midlines, and upper limits represent the $25^{\text {th }}, \mathbf{5 0}^{\text {th }}(\mathrm{median}$ ), and $75^{\text {th }}$ percentiles, respectively, of the associated data. Whiskers represent 1.5 times the interquartile range. Box colors denote ecoregions and correspond to map colors in Figure 1. 
Annual Peak SWE by Ecoregion

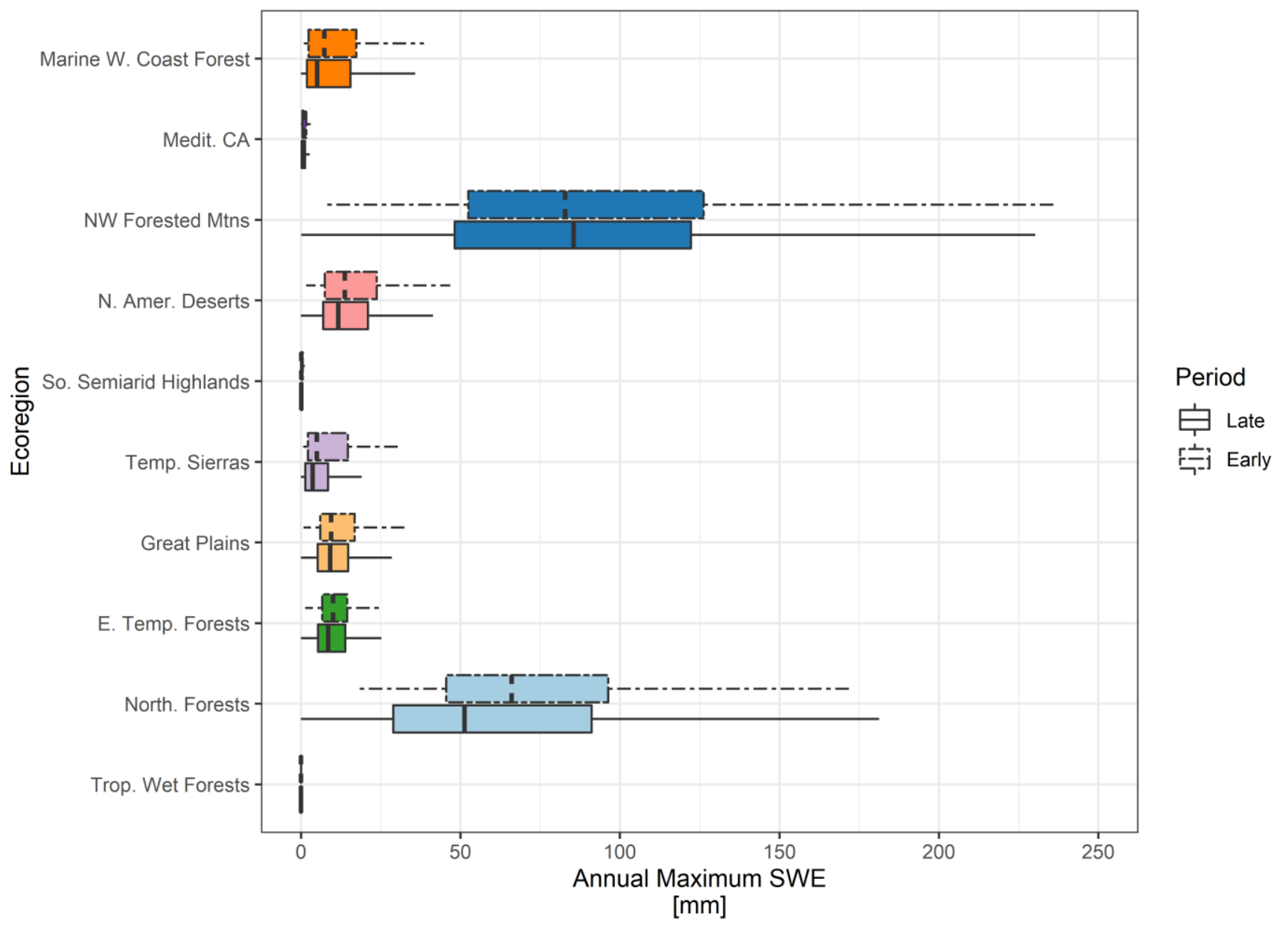

Figure A2.2: Boxplot summarizing annual peak snow water equivalent (SWE) depths by ecoregion derived from the distribution of 20 modeled estimates used in this papers. Box lower limits, midlines, and upper limits represent the $25^{\text {th }}$, $\mathbf{5 0}^{\text {th }}(\mathbf{m e d i a n})$, and $\mathbf{7 5}^{\text {th }}$ percentiles, respectively, of the associated data. Whiskers represent 1.5 times the interquartile range. 

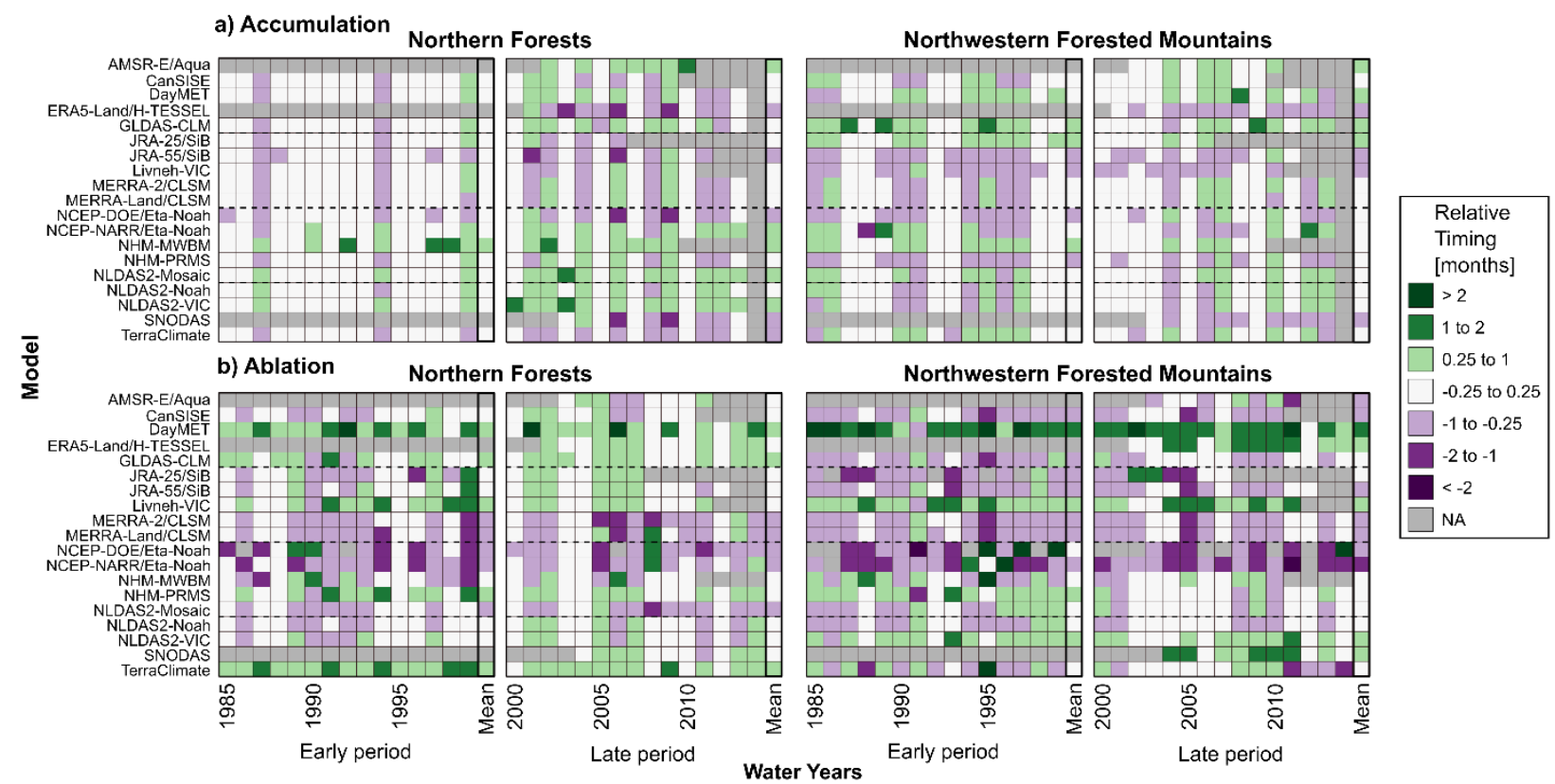

Figure A2.3: Heatmaps showing the relative timing of the beginning of snow water equivalent (SWE) accumulation (A2.3a) and ablation (A2.3b) periods for two ecoregions from 1985-2014. Relative timing is the difference between the month of the beginning of a model's accumulation or ablation period and the mean of all other model's timing. The beginning of accumulation and ablation is defined as when the rate of change of SWE between months is greater than $1 \mathrm{~mm} / \mathrm{month}$ or less than $\mathbf{- 1} \mathrm{mm} / \mathrm{month}$, respectively. 


\section{Percent Annual Positive vs. Negative Timing}

1985-2014

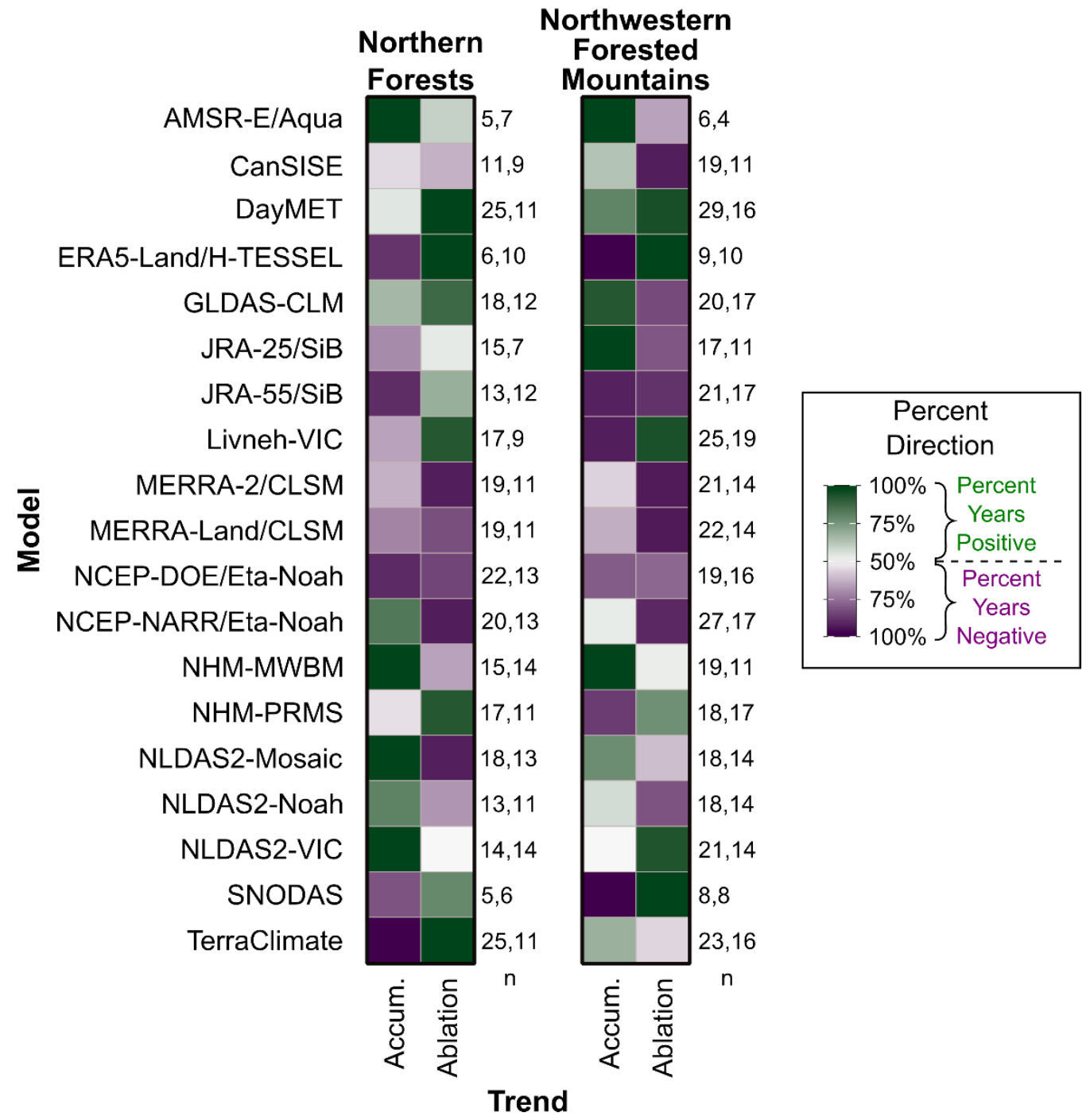

30 Figure A2.4: Heatmaps summarizing the annual relative timing values of SWE accumulation (accum.) and ablation from A2.3 for two ecoregions. Grid cells are colored by the percentage of years that have a positive relative timing (green) or by the percentage of years that have a negative relative timing (purple), whichever is greater. 


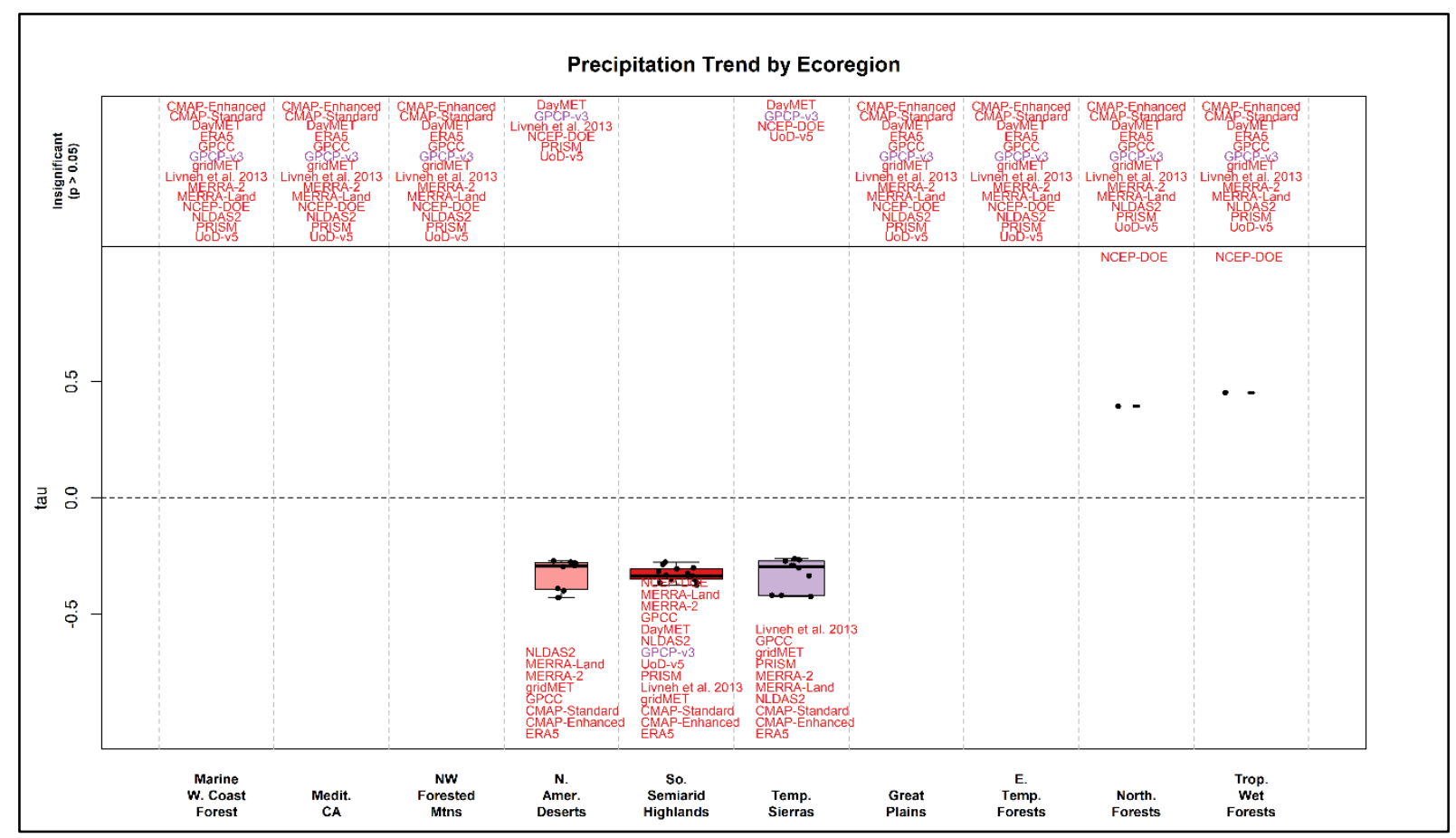

35 Figure A2.5: Boxplots of precipitation estimate Mann-Kendall tau $(\tau)$ values from 1982-2010 for 10 ecoregions. Box lower limits, midlines, and upper limits represent the $25^{\text {th }}, 50^{\text {th }}$ (median), and $75^{\text {th }}$ percentiles, respectively, of the associated data. Whiskers represent 1.5 times the interquartile range. Datasets with insignificant trends $(p>0.05)$ are listed on top. Datasets with significant trends are included within each ecoregion, ordered by magnitude of trend. Text color denotes product category: green - hydrologic model, red - reanalysis, and purple - remote sensing. 


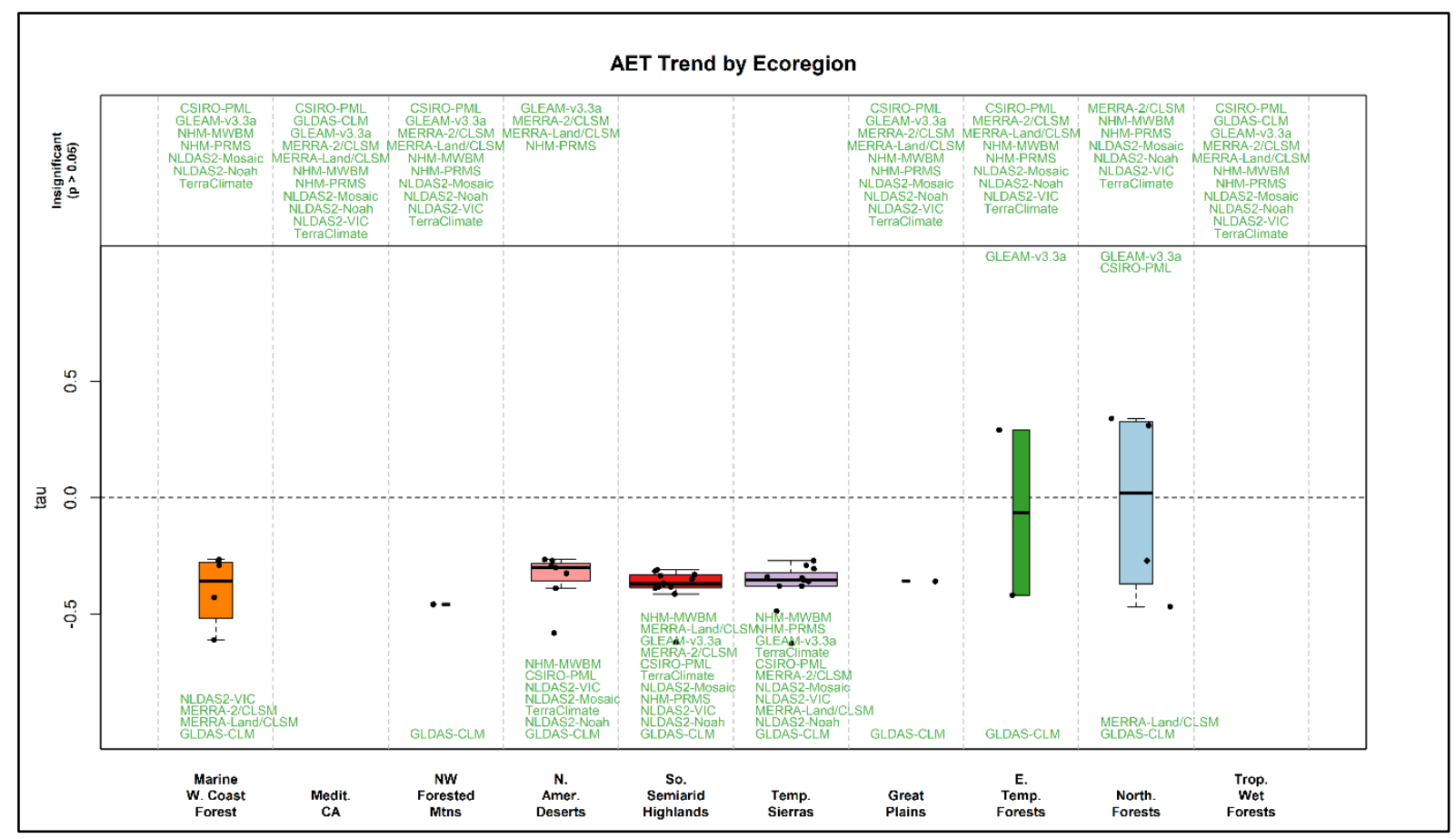

Figure A2.6: Boxplots of evapotranspiration estimate Mann-Kendall tau $(\tau)$ values from 1982-2010 for 10 ecoregions. Box lower limits, midlines, and upper limits represent the $25^{\text {th }}, \mathbf{5 0}^{\text {th }}$ (median), and $75^{\text {th }}$ percentiles, respectively, of the associated data. Whiskers represent 1.5 times the interquartile range. Datasets with insignificant trends $(p>0.05)$ are listed on top. Datasets with significant 45 trends are included within each ecoregion, ordered by magnitude of trend. Text color denotes product category: green - hydrologic model, red - reanalysis, and purple - remote sensing. 


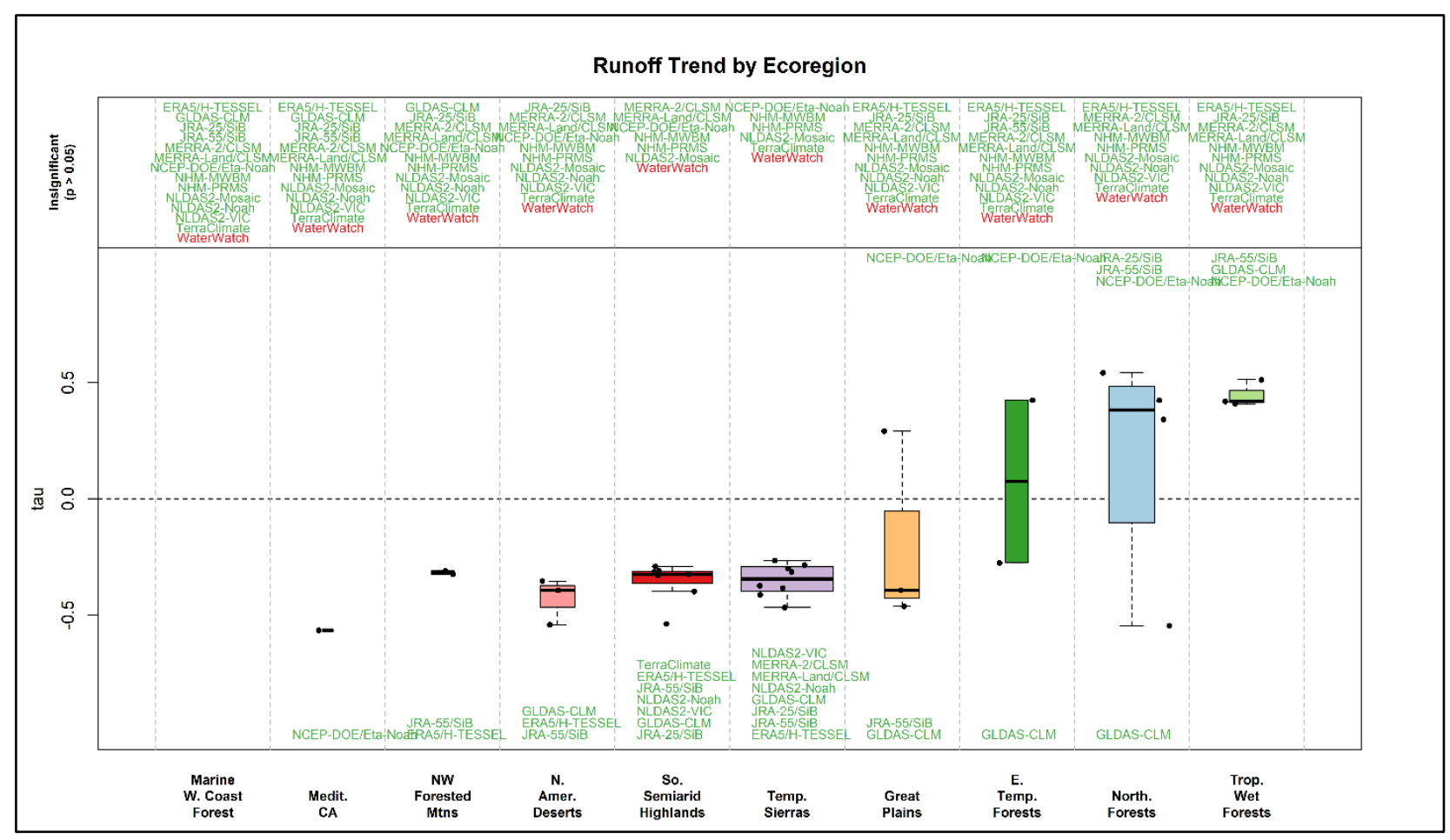

50 Figure A2.7: Boxplots of runoff estimate Mann-Kendall tau ( $\tau$ ) values from 1982-2010 for 10 ecoregions. Box lower limits, midlines, and upper limits represent the $25^{\text {th }}, 5^{\text {th }}$ (median), and $75^{\text {th }}$ percentiles, respectively, of the associated data. Whiskers represent 1.5 times the interquartile range. Datasets with insignificant trends $(p>0.05)$ are listed on top. Datasets with significant trends are included within each ecoregion, ordered by magnitude of trend. Text color denotes product category: green - hydrologic model, red - reanalysis, and purple - remote sensing. 


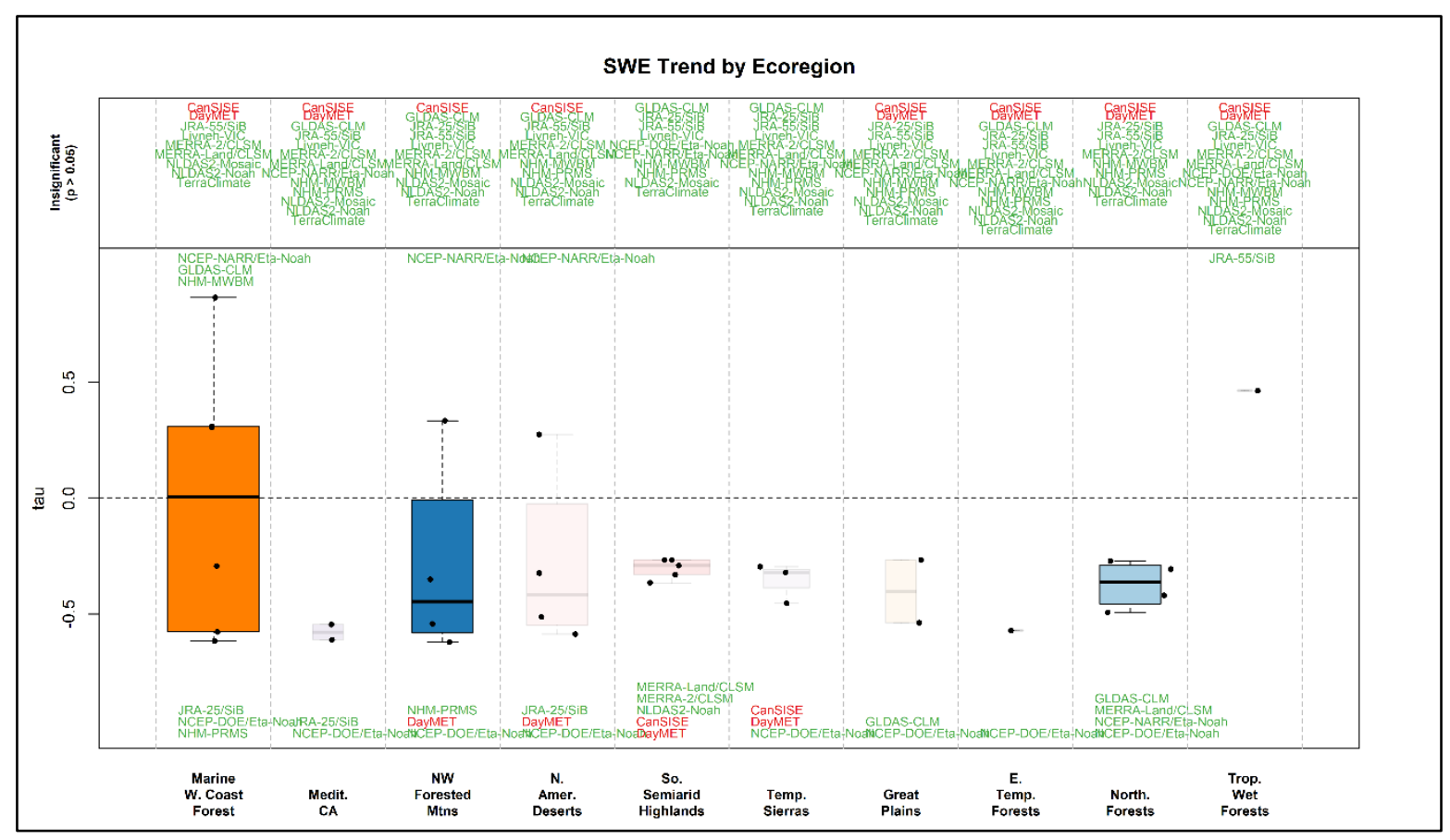

Figure A2.8: Boxplots of snow water equivalent (SWE) estimate Mann-Kendall tau ( $\tau$ ) values from $1982-2010$ for 10 ecoregions. Box lower limits, midlines, and upper limits represent the $25^{\text {th }}, \mathbf{5 0}^{\text {th }}$ (median), and $75^{\text {th }}$ percentiles, respectively, of the associated data. Whiskers represent 1.5 times the interquartile range. Datasets with insignificant trends $(p>0.05)$ are listed on top. Datasets with 60 significant trends are included within each ecoregion, ordered by magnitude of trend. Text color denotes product category: green hydrologic model, red - reanalysis, and purple - remote sensing. 


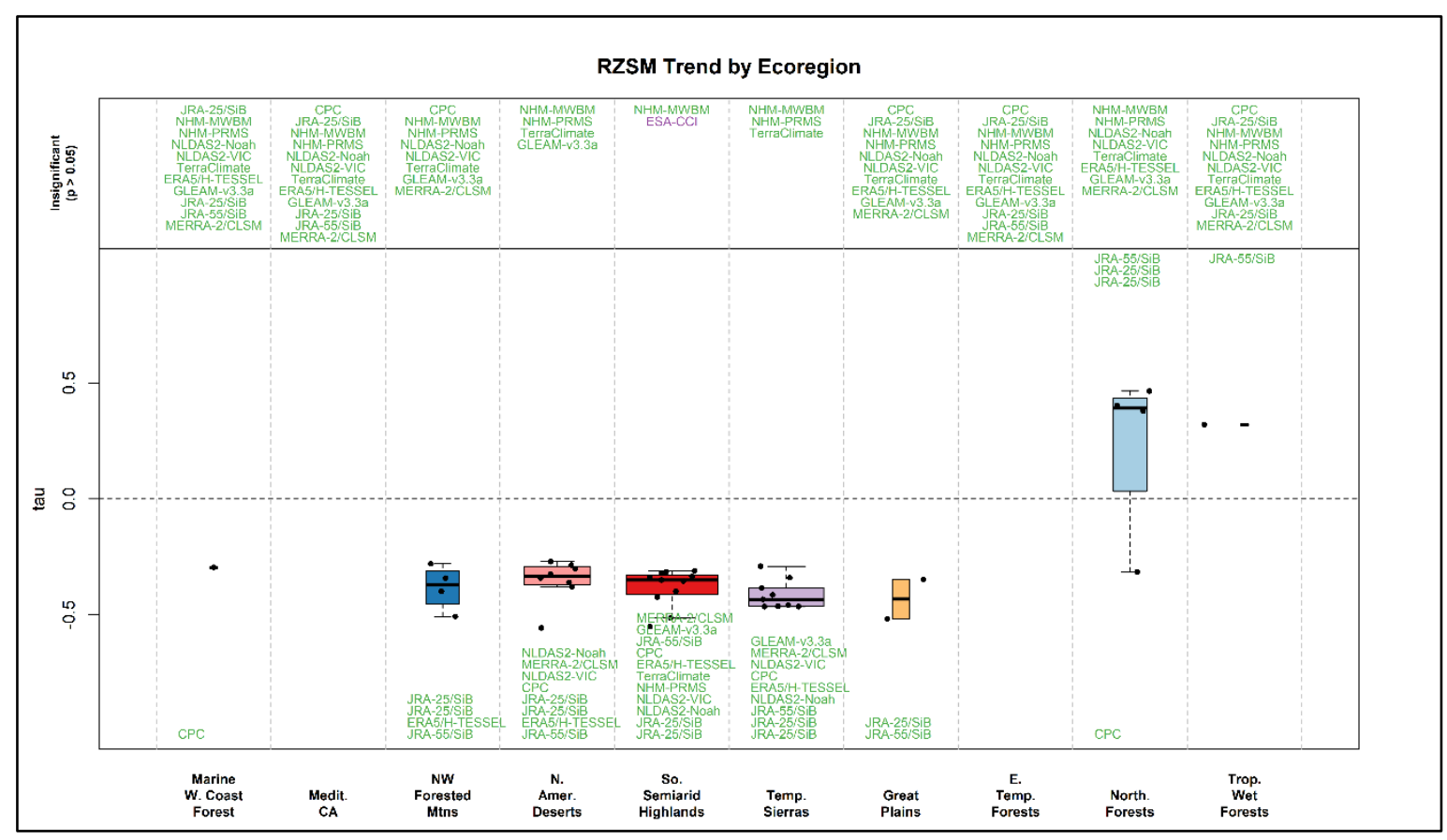

Figure A2.9: Boxplots of rootzone soil moisture estimate Mann-Kendall tau $(\tau)$ values from $1982-2010$ for 10 ecoregions. Box lower limits, midlines, and upper limits represent the $25^{\text {th }}, 50^{\text {th }}$ (median), and $75^{\text {th }}$ percentiles, respectively, of the associated data. Whiskers represent 1.5 times the interquartile range. Datasets with insignificant trends $(p>0.05)$ are listed on top. Datasets with significant trends are included within each ecoregion, ordered by magnitude of trend. Text color denotes product category: green - hydrologic model, red - reanalysis, and purple - remote sensing. 
Model Correlation against Remote Sensing Products

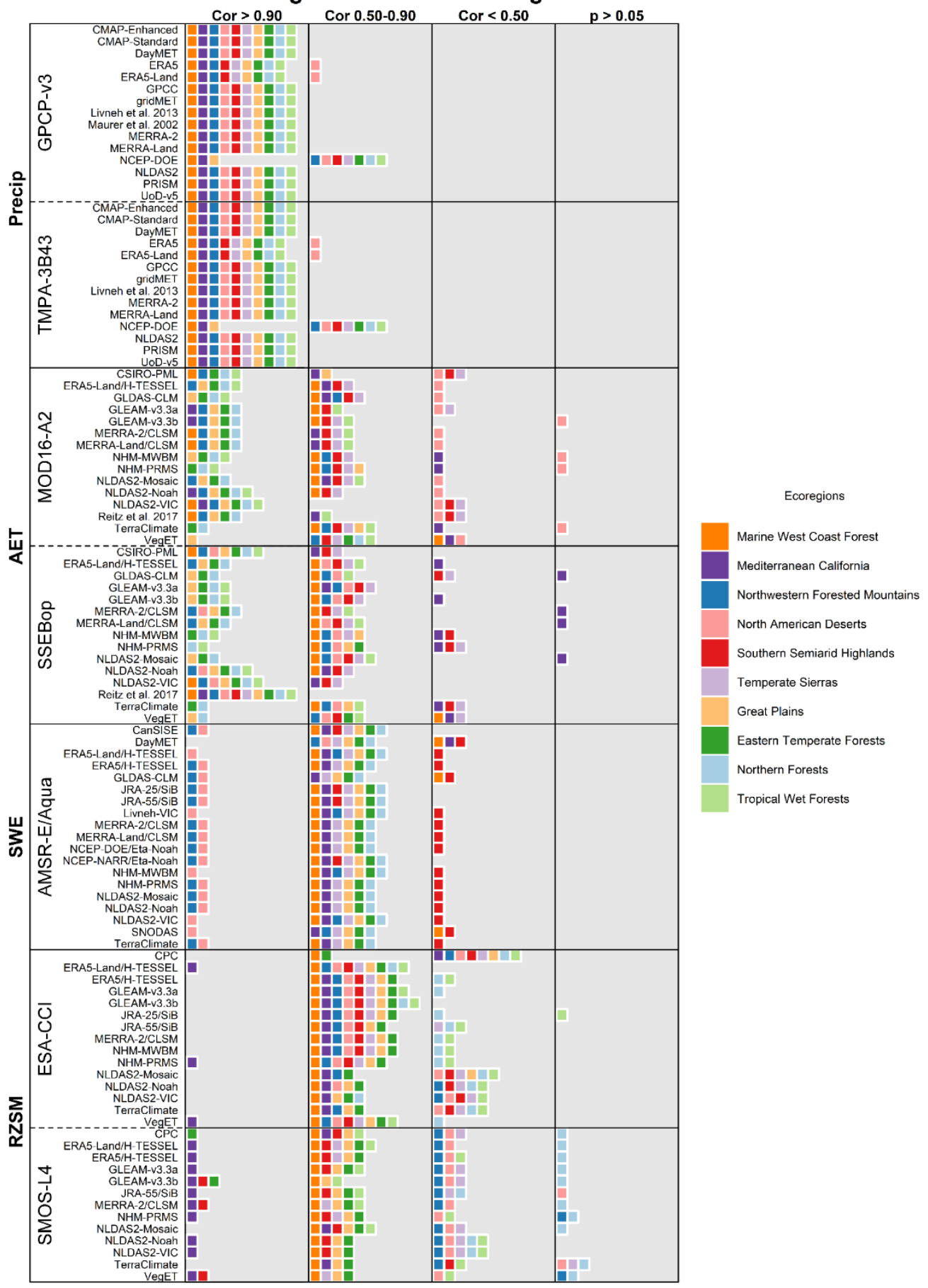

Figure A2.10: Distribution of hydrologic model and reanalysis dataset correlation against remote sensing products using Spearman's rho ( $\rho)$, provided by water budget component. Values of $\rho$ are binned by $>0.90,0.50-0.90,<0.50$, and statistically insignificant $(p>$ 
0.05). Rectangles are color-paired with their associated ecoregions (Fig. 1). Water budget components shown are precipitation (precip), actual evapotranspiration (AET), snow water equivalent (SWE), and rootzone soil moisture (RZSM). 